\title{
Factors of premarital sexual activities of literate emerging adults in Nigeria
}

\author{
Mulikat Ladi Abdulqadir Mustapha ${ }^{1}$, Rahmat Nurudeen Shuaib ${ }^{2}$ \\ ${ }^{1}$ Department of Counsellor Education, University of Ilorin, Nigeria \\ ${ }^{2}$ Counselling and Career Services Centre, Kwara State University, Nigeria \\ Corresponding author: mustapha.mla@unilorin.edu.ng
}

\section{ARTICLE INFO}

Article history

Received March 5, 2021

Revised July 13, 2021

Accepted July 29, 2021

\section{Keywords}

economic factors;

literate emerging adults;

premarital sexual activities.

\begin{abstract}
The increasing tolerance of antenuptial sexual acts among youth in contemporary society has directed research interest to its consequences on varying health outcomes. Weighing various negative effects of premarital sexual activities, inquiring the factors enhancing emerging adults' engagement in these activities is needed. This investigation focused on exploring myriad factors (grouped under six categories) of literate emerging adults' engagement in antenuptial sexual acts. This study inquired into these factors utilizing a descriptive survey, gathering data through a validated questionnaire possessing a good reliability index; from literate emerging adults in a Nigerian state. Factor analysis and regression were used for data analysis. Results emphasized all factors considered significant with biological, educational, and personal factors been more significant of literate emerging adults' sexual activities regardless of religion and ethnic background (except for economic factors). The implication of the findings is sex education planning program is needed for counselors in tertiary institutions and the community. Therefore, literate emerging adults will have an avenue to discuss the burning issue of prenuptial sexual acts and the consequences. Moreover, the sex education planning program will help literate emerging adults to understand and clarify personal values, improve their knowledge and make healthy sexual decisions.
\end{abstract}

\section{Introduction}

Emerging adulthood is a term that sociologists seek advocacy for its identification as an additional human developmental stage. The stage follows adolescence before full adulthood and spans between 18 and 30 years of youthful age (Arnett, 2000). Attributes like housing status, university/college attendance, weakening hormonal variations and development, autonomous living, self-governance, and limited reliance on adults distinguish the stage from adolescence (Arnett, 2004).

During emerging adulthood, erotic and sexuality are greatly explored and considerably favored by significant adults (Lefkowitz, Gillen, Arnett, \& Tanner, 2006; Olsho, Cohen, Walker, Johnson, \& Locke, 2009). Relationships seem more tenuous than in adulthood, and romantic relationships constantly change (Regnerus \& Uecker, 2011), focusing more on sexual behaviors that are enjoyable, moral, and appropriate for their age group (LeVay \& Valente, 2003). Contemporary youths in Nigeria experiment more than before with premarital sexual activities (Aderinola, 2013; Buhari, 2015).

Varying factors could be responsible for premarital sexual activities during emerging adulthood, especially among the literates. The factors include the belief in the nurturing 
ability of premarital sexual activities and experiences regarding skills. The belief and the experience will facilitate effective partner choice, interaction with partners, exploration of sexual behaviors, uncovering sexual uniqueness, understanding one's romantic needs and preferences (Collins, Welsh, \& Furman, 2009), a poor conception of abstinence from sex, lack of self-control and curiosity (Odebiyi, 2015).

Studies (Ayoola, 2017; Buhari, 2015; Calzo, 2013; Garcia \& Reiber, 2008; Lewis, Lee, Patrick, \& Fossos, 2007; Monto \& Carey, 2014) and reports (National Research Council and Institute of Medicine, NRCIM, 2005) attributed escalation in prenuptial sexual acts of literate emerging adults in developing countries to a logical consequence of several conditions. The conditions include the falling age at puberty, rising age at marriage, increased schooling rates, the need for youth to focus on their education/career. At the same time, they gratify their erotic desires, the penetration of mass media, historical changes in sexual norms, turbulent economic circumstances, entertainment, increasingly common ideas about individualism, the erosion of traditional social controls, peer influence, and courtship tradition. In this study, these numerous factors that promote engagement in prenuptial sexual acts are grouped into biological, economic, educational, family, personal, and social factors, whether they are significant factors of literate emerging adults' premarital sexual activities in Nigeria. Literate emerging adults are assumed to have facts regarding the consequences of unprotected sexual activities among unmarried individuals. The factors grouped under each category are provided in the appendix. Religious adherence is believed to impact individuals' attitudes to premarital sexual acts, but whether it impacts the perception of the literate emerging adults on prenuptial sexual acts has not been much dwell upon. An individual's view regarding the factors of prenuptial sexual acts could be impacted by their religious background and some stereotype orientation from one's ethnic group. The study, thus, investigated whether any of the categories of the factors will be significantly associated with respondents' religious or ethnic group than others.

There are inconsistencies in research findings regarding differences in ethnic groups and religion of practice in the review of premarital sexual behaviors. Researchers found ethnicity to be imperative in adolescents' and youth's sexual behaviors (Adetayo, 2015; Fuller \& Narasimhan, 2008; Sambisa, Curtis, \& Stokes, 2010; Sheela \& Audinarayana, 2003), while others did not (Ayoola, 2017; Azuike et al., 2015; Marston \& King, 2006; Odimegwu \& Somefun, 2017). There is still controversy underlying the mechanism through which religion affects the sexual behavior of adolescents in Nigeria. Indeed, religious values are the basis of moral prohibitions for many individuals. The teachings of the major religions in Nigeria are likely to play an imminent role in forming individual attitudes, values, and decisions. Findings regarding the influence of religion on sexual behaviors have been mixed. Researchers have documented significant effects of religion (Traditional religion, Christianity, Islam, among others) on perceived prevalence, attitude, and patterns of premarital risky sexual activities (Abboud, Flores, Redmond, Brawner, \& Sommers, 2020; Adamczyka \& Hayes, 2012; Aderinola, 2013; Akande, 2013; Muhammad, Shamsuddin, Sulaiman, Amin, \& Omar, 2017; O Wusu, 2011; Odimegwu, 2005). Omotesho (2006) and Saadu (2016) revealed insignificant variation in premarital sexual behaviors across respondents from varying religious backgrounds in Nigeria.

Literate emerging adults have been attributed with high sexual exploration and experimentation (Lefkowitz et al., 2006; Olsho et al., 2009) without commensurate readiness to assume adult roles due to fewer job opportunities after schooling. Hence, they delay marriage, but in the course of satisfying their sexual urge, they engage in cohabitation, premarital sex, and birth control. It appears that literate emerging adults in this contemporary society considered that engaging in premarital romantic relationships would help shape their intending long-term committed relationships at adulthood. However, this assertion appears unfounded considering the rate of divorce among young couples. Instead, involvement in a premarital sexual relationship has been reported to have numerous consequential effects. 
Studies reported high rates of risky sexual activities, unwanted (unintended) pregnancy, abortion, high birth rate outside wedlock and STIs including HIV/AIDs among adolescents and youth (Agunbiade \& Aransiola, 2016; Akande, 2013; Olugbenga-Bello, Adekanle, Ojofeitimi, \& Adeomi, 2010). With abundance research outcomes on the consequences of premarital sexual activities and documentation of increasing premarital sexual activities among the youth of varying educational qualification; expanding an empirical survey regarding a holistic view of various factors promoting premarital sexual activities of literate emerging adults becomes necessary with the aim of developing an all-inclusive approach in addressing this issue of premarital sexual activities among literate emerging adults.

Based on the researchers' knowledge, few studies exist in the locale that considered literate emerging adults as a population. Multiple factors were less reflected in one study regarding their influence on literate emerging adults' sexual activities. The gap observed in the previous studies that the researchers filled by investigating the factors of premarital sexual activities of literate emerging adults in Kwara State, Nigeria.

The primary purpose of this study was to investigate the factors of premarital sexual activities among literate emerging adults in Kwara state, Nigeria. In this study, literate emerging adults are individuals of marriageable age (18-30 years) but are not yet married; they might be attending or have finished school, unemployed or underemployed, partially depending on parents for their needs self-governing. This study also examined which of the perceived factors of literate emerging adults' premarital erotic activities associate significantly with the religious affiliation and ethnic group. The study provided the answer to the research question: What are the factors of premarital sexual activities of literate emerging adults? (RQ). Two research hypotheses guided the investigation:

1. Religion would not correlate with perceived factors of literate emerging adults' premarital sexual activities (H1).

2. Ethnic groups would not correlate with perceived factors of literate emerging adults' premarital sexual activities $(\mathrm{H} 2)$.

\section{Method}

The study determined what factors are assumed to be important in literate emerging adults' involvement in prenuptial sexual acts. It also looked at the association between these perceived factors and respondents' religion and ethnicity. The descriptive survey research design was adopted for the study. The population scope for this study encompasses the entire literate emerging adults in Kwara State, projected to be six hundred and eighty-eight thousand, eight hundred and twenty-eight (National Population Commission, NPC Nigeria, 2018). Therefore, a suggested sample magnitude of 384 based on the Research Advisor (2006) which was expanded by $10 \%$ (38.4) to cater to attrition, thus making a total of 423 literate emerging adults that responded to the questionnaire.

\section{Participants}

A multi-step selection process was applied to select 423 literate emerging adults following proportional stratified random sampling techniques. Literate emerging adults were purposively sampled from ministries, tertiary institutions, and government parastatals. Participants were later grouped based on the religion they practiced and their ethnic group. Nine of the sixteen Local Government Areas (LGAs) were proportionally selected from the three senatorial districts of Kwara South, North, and Central in ratio 4:3:2, respectively. Forty-seven study samples were randomly selected from each of the nine selected LGAs. The purposive sampling was only meant to select individuals that fit the description of literate emerging adults. The participants were not all necessarily engaging in premarital sexual activities. Still, they fall within the age range of emerging adults (18-30 years) who may be 
involved or know some of their colleagues who engage in premarital sexual activities. The distribution of the respondents is presented in Table 1.

Table 1

Demographic Characteristics of Respondents

\begin{tabular}{|c|c|c|}
\hline Variables & Frequency & Percentage \\
\hline \multicolumn{3}{|l|}{ Religion } \\
\hline African Trad. Rel. & 2 & .5 \\
\hline Christianity & 160 & 59.2 \\
\hline Islam & 235 & 55.2 \\
\hline Total & 397 & 100 \\
\hline \multicolumn{3}{|l|}{ Ethnicity } \\
\hline Baruba & 60 & 15.1 \\
\hline Hausa & 10 & 2.5 \\
\hline Igbo & 20 & 5.0 \\
\hline Nupe & 88 & 22.2 \\
\hline Yoruba & 219 & 55.2 \\
\hline Total & 397 & 100 \\
\hline
\end{tabular}

Out of the 423 copies of the questionnaire form administered, 397 were adequate for data analysis. So, of the 397 respondents, $2(.5 \%)$ were African Traditional Religion adherents, 160 (40.3\%) were Christians, while 235 (59.2\%), which forms the majority, were Muslims. With respect to the ethnic group, the majority numbering 219 (55.2\%) of the respondents were Yoruba, $10(2.5 \%)$ were Hausa tribe, 20 (5.0\%) were Igbo tribe, $88(22.2 \%)$ were from Nupe tribe, while $60(15.1 \%)$ represents the Baruba tribe in the North Central Nigeria where this study was conducted.

\section{Procedures}

In administering the questionnaire forms, the prospective participants were instructed regarding the criteria for participation in the study. These include the ability to read and write, being within the age bracket of individuals who can marry (18-30 years) but not married. Individuals who do not meet the criteria were excluded from participation.

\section{Instruments}

Researchers developed a self-report titled "Factors of Premarital Sexual Activities Questionnaire," which was employed to amass data for the inquiry. It has segments: A and B. The first gathered respondents' demography (ethnicity and religion). At the same time, the second segment has thirty items grouped into six factors (biological, social, family, educational, economic, and personal) of premarital sexual activities of literate emerging adults. The instrument has a stem "In my perception, the following factors are responsible for premarital sexual activities among literate emerging adults". The example of an item in each factor is as follows: genetic inheritance (biological factors); peer influence (social factor); parenting styles (family factor); delay in marriage as a result of schooling (educational factor); the need to sustain economic hardship (economic factor); curiosity to experiment with sex (personal factor). The content of the instrument was validated by five experts from the researchers' department. The Cronbach alpha procedure was applied to determine the instrument's reliability, and a coefficient value of .72 was obtained. Hence, the instrument was adjudged reliable for use.

\section{Data Analysis}


The data gathered were scored and analyzed using the Statistical Package for Social Sciences (SPSS) software version 23. The statistical tools employed are percentage, factor analysis, and regression.

\section{Results}

In regards to the research question of this study, Table 2 depicted the summary of factor analysis results using Principal Axis Factoring and Orthogonal Varimax Rotation. The factor analysis was conducted to identify the significant factors in premarital sexual activities of literate emerging adults in North-Central Nigeria.

Table 2

Principal Components on Factors of Premarital Sexual Activities of Literate Emerging Adults

\begin{tabular}{llrrr}
\hline & Factor & \multicolumn{3}{c}{ Components } \\
\cline { 3 - 5 } & & 1 & 2 & 3 \\
\hline 1 & Biological factor & .892 & & \\
2 & Educational factor & .656 & & \\
3 & Personal factors & & .717 & \\
4 & Social factors & & .902 & \\
5 & Family factors & & & -.674 \\
6 & Economic factors & 1.998 & 1.140 & .745 \\
& Eigen values & 33.297 & 19.004 & 16.959 \\
\hline
\end{tabular}

Notes: Kaiser-Meyer-Olkin Measure Sampling Adequacy $=.573 ; X=341.715 ; \mathrm{df}=15$; Bartlett's Test of Sphericity Significance $=.000 ; \mathrm{EV}=$ Eigen value; $\mathrm{TVE}=$ Total variance explained

Table 2 shows that all KMO values for each of the factors (>.90) were well above .5, and the Kaiser-Meyer-Olkin Measure (KMO) was .573, indicating that the data was sufficient for exploratory factors analysis. Bartlett's test of sphericity chi-square $(15)=341.715, \mathrm{p}<$ .000 , reflected patterned relationships among the six factors. Three factors were gained by employing an eigenvalues cut-off of .50. These factors explain a percentage variance of $33.297,19.004$, and 16.959, respectively. This result is indicated by the factor loading after rotation using a significant factor criterion of .50. The factor loading of each factor of premarital sexual activities among emerging adults is social factors (.902), biological factors (.892), economic factors (.745), personal factors (.717), educational factors (.656), and family factors (-.674). However, going by the loaded rotation values, the most significant premarital sexual activities factors of literate emerging adults in this model are social factors, biological factors, and economic factors. The results obtained do not indicate that other factors considered in the study are insignificant. All the items that make up each of the factors were derived from empirical investigations conducted in similar locations to emphasize that the items are recognized and found to be responsible for literate emerging adults' sexual activities.

Table 3 summarizes the multiple regression analysis for premarital sexual activities factors as correlates of respondents' religion as in hypothesis 1 . The $F(6,390)=.675$ indicates that the regression model did not fit the data. The finding indicates that respondents' perceived factors of premarital sexual activities do not correlate with their religious affiliation. The $\beta$ values of biological, social, family, educational, economic, and personal factors $(.003,-.010, .015,-.007,-.010$ and $.008 ; p=>0.05)$ respectively, as factors of literate emerging adults' premarital sexual activities are insignificant. Hence, the hypothesis is retained. This result means the perception of respondents regarding factors responsible for literate emerging adults' sexual activities is not related to the religion they practice. 
Table 3

Multiple Regression Analysis of Premarital Sexual Activities Factors as Correlates of Respondents'Religion

\begin{tabular}{cccccc}
\hline Variables & \multicolumn{5}{c}{ Religion } \\
\cline { 2 - 5 } & $\mathrm{R}$ & $\mathrm{R}^{2}$ & $\mathrm{~F}$ & $\mathrm{~B}$ & $\mathrm{p}$ \\
\hline Constant & .101 & .010 & .675 & 1.598 & .000 \\
Biological & & & .003 & .810 \\
Social & & & -.010 & .466 \\
Family & & & .015 & .146 \\
Educational & & & -.007 & .402 \\
Economic & & & -.010 & .349 \\
Personal & & & .008 & .409 \\
\hline
\end{tabular}

Table 4 summarizes the multiple regression analysis for premarital sexual activities factors as correlates of respondents' ethnic groups as in hypothesis 2 . The $R$ value of .191 has a low degree of correlation. While $R^{2}$ value of .037 indicates $3.7 \%$ of the total variation in the factors perceived to be responsible for literate emerging adults' premarital sexual activities can be explained by their ethnic groups, this is also low. The $\mathrm{F}(6,390)=2.471$ indicates that regression model fit the data. This finding means the premarital sexual factors correlate with the respondents' ethnic groups. The $\beta$ values of biological, social, family, educational and personal factors $(.070, .028,-.033,-.021$ and $-.014 ; \mathrm{p}=>.05)$ respectively, are insignificant. In contrast, a significant $\beta=-.088 ; \mathrm{p}<.05$, for economic factor, indicates the correlation with literate emerging adults' ethnic groups. Hence, the hypothesis is retained for other factors but rejected concerning economic factors. This result means that the respondents' perception regarding factors of premarital sexual activities of literate emerging adults is related to the ethnic group of the respondents except for the economic factor.

Table 4

Multiple Regression Analysis of Premarital Sexual Activities Factors as Correlates of Respondents' Ethnic Groups

\begin{tabular}{cccccc}
\hline Variables & \multicolumn{5}{c}{ Ethnic Group } \\
\cline { 2 - 6 } & $\mathrm{R}$ & $\mathrm{R} 2$ & $\mathrm{~F}$ & $\mathrm{~B}$ & $\mathrm{p}$ \\
\hline Constant & .191 & .037 & 2.471 & 1.717 & .027 \\
Biological & & & .070 & .051 \\
Social & & & .028 & .520 \\
Family & & & -.033 & .322 \\
Educational & & & .021 & .453 \\
Economic & & & -.088 & .013 \\
Personal & & & -.014 & .660 \\
\hline
\end{tabular}

\section{Discussion}

The study's findings revealed all the premarital sexual activities factors (biological, educational, economic, family, personal and social) as significant. However, biological, social, and economic factors are more significant factors of premarital sexual activities of literate emerging adults in Kwara State. In this model, literate emerging adults emphasized that a drop in the age of puberty and unhealthy sexual desire are the major biological factors predisposing literate emerging adults to premarital sexual activities. This finding is in line with the findings of previous studies (Ajiboye, Aina, Oyebanji, \& Awoniyi, 2014; Garcia \& Reiber, 2008; Muhammad et al., 2017). Muhammad et al. (2017) found biological factors 
powerful to influence youth engagement in premarital sexual activities irrespective of their engagement in religious activities. The phase of the lifespan of the youth is significant in prompting their involvement in prenuptial sexual activities (Ajiboye et al., 2014; Garcia \& Reiber, 2008). They noted that the unique development of sex organs and structure, high sexual urge that accompanied the adolescent stage, and decline in the age of puberty as biological factors responsible for adolescents' involvement in such activities.

The study's findings also revealed social factors as one of the more significant factors of literate emerging adults' premarital sexual activities. These results corroborate the findings of Aderinola (2013); Ayoola (2017); Ghaffari et al. (2019); Onipede (2009); Sambisa et al. (2010); Thanh-Hang \& Edwin (2019), which revealed media (satellites and internet) and social changes as social factors predisposing tertiary institution students' involvement in premarital sexual deeds. Current trends around the globe have to change the social norms regarding premarital sex. The strong cultural and religious beliefs regarding abstinence from sexual acts has been relaxed especially among supposed adults (literate emerging adults) who are delayed into entering family life pattern based on varying factors (education, unemployment, poverty, etc.). Thereby the acceptance of social factors as a major factor of emerging adults' involvement in premarital sexual activities is in order. The widespread use and misuse of the internet among other media has also been a paramount social factor predicting literate emerging adults' involvement in premarital sexual acts. It is glaring that adolescents and young adults are so much engrossed in various media in obtaining different kinds of information, learning, and interacting. Many of the materials they are exposed to can prompt them to engage in premarital sexual acts. It is, therefore, not surprising that the influence of media appears as a social factor of the acts.

The findings have been revealed that literate emerging adults from low economic family settings who desire to be financially buoyant before marriage and love materialism are likely to engage in premarital sexual activities to meet their needs and sustain economic adversity. The results are in line with the submissions of Aderinola (2013) who found economic hardship as one of the significant factors in premarital sexual acts of secondary school students.

The outcomes of this study pointed out that respondents, irrespective of their religious background and ethnicity, are similar in their perception of factors responsible for literate emerging adults' premarital sexual activities except for economic factors. The economic factor is related to respondents' ethnicity, as found in previous reviews' outcomes (Aderinola, 2013; Akande, 2013; Ayoola, 2017; Muhammad et al., 2017; Omotesho, 2006; Saadu, 2016). The researchers considering varying samples and settings found that the perceptions of their respondents on the prevalence of, attitude toward, causes, and consequences of premarital sexual activities are not impacted by the religion they practiced. On the contrary, researchers reported significant religious difference in the premarital sexual activities of individuals residing in a cultured Muslim nation (Adamczyka \& Hayes, 2012; Agha, Hutchinson, \& Kusanthan, 2006; Somefun, 2019). The difference in the findings could be because this particular study inquired about the perception of literate emerging adults from differing religious affiliations regarding factors of premarital sexual activities while other studies sought for impact of religious differences and level of religiosity on youth' engagement in premarital sex. While religion or level of religiosity might impact the sexual practice of individuals, individuals from the differing religious background may view the factors of premarital sexual activities in the same way.

Regarding ethnicity, researchers found ethnicity to be imperative in adolescents' sexual behaviors (Adetayo, 2015; Fuller \& Narasimhan, 2008; Sambisa et al., 2010; Sheela \& Audinarayana, 2003), while others did not (Ayoola, 2017; Azuike et al., 2015; Marston \& King, 2006; Odimegwu \& Somefun, 2017). Sambisa et al. (2010) noted that certain sexual behaviors (unsafe sexual practice, self-restraint, usage of condoms) are peculiar to definite Zimbabwean youth. Sheela \& Audinarayana (2003) revealed that Hindu females from middle 
and higher classes like the Yoruba or Igbo ethnic groups might likely marry after completing their education, thereby predisposing them to increase risk of premarital sexual acts. In contrast, those at the lower socioeconomic level are likely to marry earlier (Fuller \& Narasimhan, 2008). The findings of this study regarding the perception of economic factor impact on premarital sexual acts of literate emerging adults are significantly associated with respondents' ethnicity is justified by the past reviews. Perception of the respondents regarding all the factors (biological, educational, family, personal and social) of premarital sexual activities of literate emerging adults are not related to their ethnicity except with regard to economic factors which Sheela \& Audinarayana (2003); Fuller \& Narasimhan (2008); Adetayo (2015) had earlier asserted.

This study increases investigation regarding sexual behavior by exploring a wide range of factors responsible for sexual behaviors of literate emerging adults. The study also focused on whether respondents' perceptions of these factors will be associated with their religious or ethnic groupings. However, this study has a limitation. Only the perception of the literate emerging adults on the factors of premarital sexual activities is measured. Despite this limitation, this study has several recommendations for stakeholders in regards to premarital sexual behaviors. Parents should provide children with a nurturing environment that promotes positive self-control on risky behaviors as they grow. Although literate emerging adults are matured and educated, stakeholders should engage them in discussion (sexuality education) to enlighten and guide them on the aftermaths of premarital sexual deeds and being too materialistic. While counselors should engage literate emerging adults across ethnic and religious groups on effective management of their sexual urge since biological factors cannot be put on hold; they should also help literate emerging adults build healthy self-esteem, shape their perception and equip them with life skills that will empower them to make reasonable decisions regarding healthy sexual conduct.

\section{Conclusion}

From the findings of this study, it can be inferred that all the factors considered in the study are significant, with social, biological, and economic factors been more significant factors responsible for premarital sexual activities of literate emerging adults in Kwara State, Nigeria. Media such as the internet (social factor) exposes emerging adults to sexual content through unsolicited adverts, music laden with sexual messages, pornography in movies, leading to unhealthy sexual desire (biological factor). These coupled with societal acceptance of premarital sexual acts as social norms (social factor) predispose literate emerging adults into sexual activities. Literate emerging adults from the low economic family setting that desire to be financially buoyant before marriage and love materialism are likely to engage in premarital sexual activities during economic adversity. Literate emerging adults across religious backgrounds and ethnic groups hold similar views regarding factors responsible for literate emerging adults' sexual activities. However, they differ regarding their views on economic factors. The findings are significant for the value reorientation on sexual behavior, need to understand the implications of media on unhealthy sexual desire. Literate emerging adults should find means of gainfully engaging in economic venture and reduce materialism.

\section{References}

Abboud, S., Flores, D., Redmond, L., Brawner, B. M., \& Sommers, M. S. (2020). Sexual attitudes and behaviours among Arab American young adults in the USA. Culture, Health \& Sexuality, 1-17. https://doi.org/10.1080/13691058.2020.1788163

Adamczyka, A., \& Hayes, B. E. (2012). Religion and sexual behaviors: Understanding the 
influence of Islamic cultures and religious affiliation for explaining sex outside of marriage. American Sociological Review, 77(5), 723-746. https://journals.sagepub.com/doi/pdf/10.1177/0003122412458672

Aderinola, B. S. (2013). Prevalence of, and attitude towards premarital sexual activities as expressed by secondary school students in Kwara State, Nigeria. University of Ilorin.

Adetayo, S. T. (2015). Predictors of premarital sexual behaviour among in-school adolescents in Nigeria. University of Ilorin.

Agha, S., Hutchinson, P., \& Kusanthan, T. (2006). The effects of religious affiliation on sexual initiation and condom use in Zambia. Journal of Adolescent Health, 38(5), 550 555. https://doi.org/10.1016/j.jadohealth.2005.04.012

Agunbiade, O. M., \& Aransiola, J. O. (2016). Patterns of risky sexual behaviours among emerging adults in intimate sexual relationships in two tertiary institutions in southwestern Nigeria. Journal of Child \& Youth Services, 37(3), 271-286. https://doi.org/10.1080/0145935X.2015.1099429

Ajiboye, S. K., Aina, J. S., Oyebanji, T. O., \& Awoniyi, S. A. (2014). Possible causes of premarital sex among youth as perceived by lecturers of the University of Ilorin. European Journal of Educational Sciences, 1(4), 1-9.

Akande, A. E. (2013). Patterns and consequences of risky sexual behaviour among secondary school students in Kwara state, Nigeria. Unpublished Master Dissertation. University of Ilorin.

Arnett, J. J. (2000). Emerging adulthood: A theory of development from the late teens through twenties. American Psychologist, 55(5), 469-480. https://doi.org/10.1037/0003-066X.55.5.469

Arnett, J. J. (2004). Emerging adulthood: The winding road from the late teens through the twenties. Oxford University Press.

Ayoola, V. A. (2017). Influence of social media and peer pressure on sexual behaviours of undergraduates in Kwara State, Nigeria. Unpublished Master Dissertation. University of Ilorin.

Azuike, E. C., Iloghalu, I. C., Nwabueze, S. A., Emelumadu, O. F., Balogun, J. S., \& Azuike, E. D. (2015). Sexual behaviour among senior secondary school students in Nnewi North and Nnewi South Local Government Areas of Anambra State, South-Eastern Nigeria. European Journal of Preventive Medicine, 3(2), 26-33. https://doi.org/10.11648/j.ejpm.20150302.13

Buhari, S. A. (2015). Causes and consequences of premarital sex as expressed by female inschool adolescents in Kwara State, Nigeria. Unpublished Master Dissertation. University of Ilorin.

Calzo, J. P. (2013). Hookup sex versus romantic relationship sex in college: Why do we care and what do we do? Journal of Adolescent Health, 52(5), 515-516. https://doi.org/10.1016/j.jadohealth.2013.03.001

Collins, W. A., Welsh, D. P., \& Furman, W. (2009). Adolescent romantic relationships. Annual Review of Psychology, 60, 631-652. https://psycnet.apa.org/doi/10.1146/annurev.psych.60.110707.163459

Fuller, C. J., \& Narasimhan, H. (2008). Companionate marriage in India: The changing marriage system in a middle-class Brahman Subcaste. Journal of the Royal Anthropological Institute, 14(736-754). https://doi.org/10.1111/J.14679655.2008.00528.X

Garcia, J. R., \& Reiber, C. (2008). Hook-up behavior: A biopsychosocial perspective. Journal of Social, Evolutionary, and Cultural Psychology, 2(4), 192-208. https://dx.doi.org/10.1037/h0099345 
Ghaffari, M., Rakhshanderou, S., Gharlipour, Z., Khalajabadi-Farahani, F., Ramezani, T., \& Izadkhah, F. (2019). Students' perspective on factors influencing premarital sexual intercourse. Journal of Holistic Nursing and Midwifery, 30(2), 111-119. https://doi.org/10.32598/jhnm.30.2.111

Lefkowitz, E. S., Gillen, M. M., Arnett, J. J., \& Tanner, J. L. (2006). Sex is just a normal part of life: Sexuality in emerging adulthood. In J. J. Arnett \& J. L. Tanner (Eds.). In Emerging adults in America: Coming of age in the 21st century (pp. 235-255). American Psychological Association.

LeVay, S., \& Valente, S. M. (2003). Human sexuality. Sinauer Associates.

Lewis, M. A., Lee, C. M., Patrick, M. E., \& Fossos, N. (2007). Gender-specific normative misperceptions of risky sexual behavior and alcohol-related risky sexual behavior. Sex Roles: A Journal of Research, 57(1-2), 81-90. https://doi.org/10.1007/s11199-0079218-0

Marston, C., \& King, E. (2006). Factors that shape young people's sexual behaviour: A systematic review. Lancet (London, England), 368(9547), 1581-1586. https://doi.org/10.1016/S0140-6736(06)69662-1

Monto, M. A., \& Carey, A. G. (2014). A new standard of sexual behavior? Are claims associated with the "hookup culture" supported by general social survey data? Journal of Sex Research, 51(6), 605-615. https://doi.org/10.1080/00224499.2014.906031

Muhammad, N. A., Shamsuddin, K., Sulaiman, Z., Amin, R. M., \& Omar, K. (2017). Role of Religion in Preventing Youth Sexual Activity in Malaysia: A Mixed Methods Study. Journal of Religion and Health, 56(6), 1916-1929. https://doi.org/10.1007/s10943016-0185-z

National Population Commission (NPC,Nigeria). (2018). Nigeria demographic and health survey. Nigeria. Retrieved from https://dhsprogram.com/pubs/pdf/FR359/FR359.pdf

National Research Council and Institute of Medicine (NRCIM). (2005). Growing up global: The changing transitions to adulthood in developing countries. The National Academies Press https://doi.org/10.17226/11174

O Wusu, O. (2011). Religion, religiosity and adolescent risky sexual health behaviour in Lagos metropolis, Nigeria. Journal of Humanities and Social Sciences, 3(1), 48-55. https://doi.org/10.4314/ijhss.v3i1.69507

Odebiyi, M. F. (2015). Patterns and causes of premarital sexual activities as perceived by tertiary institution students in Niger State, Nigeria. Unpublished Master Dissertation. University of Ilorin.

Odimegwu, C. (2005). Influence of religion on adolescent sexual attitudes and behaviour among Nigerian university students: Affiliation or commitment? African Journal of Reproductive Health, 9, 125-140.

Odimegwu, C., \& Somefun, O. (2017). Ethnicity, gender and risky sexual behaviours among Nigerian youth: An alternative explanation. Reproductive Health, 14(1). https://doi.org/10.1186/s12978-017-0284-7

Olsho, L., Cohen, J., Walker, D. K., Johnson, A., \& Locke, G. (2009). National Survey of adolescents and their parents: Attitudes and opinions about sex and abstinence. ABT Associated.

Olugbenga-Bello, A., Adekanle, D., Ojofeitimi, E., \& Adeomi, A. (2010). Barrier contraception among adolescents and young adults in a tertiary institution in Southwestern Nigeria: A cross-sectional descriptive study. International Journal of Adolescent Medicine and Health, 22(2), 321-330. https://doi.org/10.1515/IJAMH.2010.22.2.321

Omotesho, B. A. (2006). A study of the sexual behaviour of university undergraduate 
students in Southwestern. Nigeria Journal of Social Sciences, 12(2), 129-133. https://doi.org/10.1080/09718923.2006.11978380

Onipede, W. (2009). Mass media and sexual health behaviour of college students in Nigeria: A study of Lagos State University. East African Journal of Public Health, 6(3), 303308.

Regnerus, M., \& Uecker, J. (2011). Premarital sex in America: How young Americans meet, mate, and think about marrying. Oxford University Press.

Saadu, Y. O. (2016). Sexual behaviour and contraceptive use among students of tertiary institutions in Kwara State, Nigeria. Unpublished Master Dissertation. University of Ilorin.

Sambisa, W., Curtis, S. L., \& Stokes, S. C. (2010). Ethnic differences in sexual behaviour among unmarried adolescents and young adults in Zimbabwe. Journal of Biosocial Science, 42(1), 1-25. https://doi.org/10.1017/S0021932009990277

Sheela, J., \& Audinarayana, N. (2003). Mate selection and female age at marriage: A micro level investigation in Tamil Nadu, India. Journal of Comparative Family Studies, 34(4), 497-508. https://doi.org/10.3138/jcfs.34.4.497

Somefun, D. O. (2019). Religiosity and sexual abstinence among Nigerian youth: Does parent religion matter? BMC Public Health, 19, 416. https://doi.org/10.1186/s12889019-6732-2

Thanh-Hang, D., \& Edwin, R. V. T. (2019). Factors influencing engagement in premarital sex among Vietnamese young adults: A qualitative study. Journal of Adolescent Medicine and Health. https://doi.org/10.1515/ijamh-2018-0201

The Research Advisor. (2006). Sample size table. Retrieved from https://www.researchadvisors.com/tools/SampleSize.htm 